\title{
Chronic metabolic responses of postpartal dairy cows to subcutaneous glucagon injections, oral glycerol, or both ${ }^{1}$
}

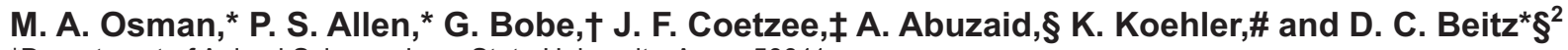 \\ *Department of Animal Science, lowa State University, Ames 50011 \\ †Department of Animal Sciences, Oregon State University, Corvallis 97331 \\ ‡Department of Veterinary Clinical Sciences, Kansas State University, Manhattan 66506 \\ $\S$ Department of Biochemistry, Biophysics, and Molecular Biology, and \\ \#Department of Statistics, lowa State University, Ames 50011
}

\section{ABSTRACT}

We examined the long-term effects of daily subcutaneous injections of $15 \mathrm{mg}$ of glucagon during the first $14 \mathrm{~d}$ postpartum with or without coadministration of $400 \mathrm{~mL}$ of pure glycerol orally on blood metabolites and hormones and liver composition of Holstein dairy cows during early lactation. Fourteen multiparous cows with body condition score of $\geq 3.5$ points ( $1-5$ point scale) were assigned randomly to one of 4 treatment groupssaline, glucagon, glycerol, or glucagon plus glycerol. Fatty liver syndrome was induced by feeding cows a dry-cow ration supplemented with $6 \mathrm{~kg}$ of cracked corn daily during the last 6 wk of the dry period. Compared with saline treatment $(\mathrm{n}=3)$, coadministration of glucagon and glycerol $(\mathrm{n}=4)$ increased plasma glucose and insulin and decreased plasma nonesterified fatty acid concentrations in both treatment weeks, whereas glucagon alone $(\mathrm{n}=3)$ produced similar changes plus a decrease in plasma $\beta$-hydroxybutyrate in the second week only. No significant changes were observed for the glycerol alone treatment $(\mathrm{n}=4)$. We conclude that a single daily dose of glycerol for the first $14 \mathrm{~d}$ postpartum may potentiate the action of glucagon in the first treatment days to alleviate some symptoms of fatty liver syndrome, such as the increase in plasma nonesterified fatty acids and the decrease in plasma glucose and insulin, in Holstein dairy cows after parturition. Key words: glucagon, glycerol, metabolism

Received September 9, 2009.

Accepted March 30, 2010.

${ }^{1}$ This is a publication of the Iowa Agriculture and Home Economics Experiment Station, Ames, Project Number 3801. A preliminary report has been presented [J. Dairy Sci. 89 (Suppl. 1):266, 2006].

${ }^{2}$ Corresponding author: dcbeitz@iastate.edu

\section{INTRODUCTION}

Earlier studies have shown that multiple glucagon injections may prevent (Nafikov et al., 2006) and treat (Bobe et al., 2003a) experimentally induced fatty liver syndrome (FLS) in Holstein dairy cows during the postpartal period. Glucagon alleviates some symptoms of FLS in part by upregulating hepatic gluconeogenesis through increased gene expression of phosphoenolpyruvate carboxykinase and pyruvate kinase (Bobe et al., 2009), which, in turn, increases plasma glucose and insulin and decreases plasma NEFA concentrations (Hippen et al., 1999; Bobe et al. 2003b; Nafikov et al., 2006). The low DMI (70\% of normal intake) in peripartal cows, however, results in a negative energy balance and may limit the availability of the gluconeogenic precursors (Doepel et al., 2002; Hayirli et al., 2002). The use of the gluconeogenic precursors such as propylene glycol, propionate salts, and amino acids to accelerate gluconeogenesis and ameliorate negative energy balance has not been successful (Greenfield et al., 2000; Hoedemaker et al., 2004). Exogenous glucagon may be required to convert sufficient gluconeogenic precursors to glucose during the peripartal period.

Glycerol is metabolized in the rumen and liver to VFA and intermediates of gluconeogenesis and glycolysis (Remond et al., 1993; Goff and Horst, 2001) that could be used to produce glucose or energy in the form of ATP to alleviate the peripartal negative energy balance. Furthermore, absorbed glycerol may be converted in the liver to $\alpha$-glycerol phosphate ( $\boldsymbol{\alpha}$-GP), which can be used to esterify excess NEFA into triacylglycerol (TAG). Previously, we showed that oral glycerol may potentiate the preventive effect of glucagon especially after the first glucagon injection by increasing plasma glucose, insulin, and TAG and decreasing plasma concentrations of NEFA and BHBA (Osman et al., 2008). The objective of this study was to examine the time course of the changes in plasma metabolites and liver lipids in Holstein dairy cows induced with experimental 
FLS and treated with glucagon, glycerol, or both for a 14-d treatment period.

\section{MATERIALS AND METHODS}

\section{Experimental Design}

Details about experimental design and plasma sampling and analysis were described previously (Osman et al., 2008). Briefly, 14 multiparous Holstein cows with a BCS $\geq 3.5$ were given ad libitum access to a dry-cow TMR supplemented with $6 \mathrm{~kg}$ of cracked corn during the last 6 wk of the dry period to induce FLS. Following parturition, experimental cows were housed in a sand-bedded tie stall and offered ad libitum access to an NRC (2001) recommended TMR for high-producing dairy cows twice a day at 0900 and $1500 \mathrm{~h}$. Starting $4 \mathrm{~h}$ after parturition, 14 cows were injected s.c. every $8 \mathrm{~h}$ for $13 \mathrm{~d}$ and $16 \mathrm{~h}$ apart on $\mathrm{d} 14$ and received a single injection on d 15 postpartum with $60 \mathrm{~mL}$ of 0.9 $M \mathrm{NaCl}$ solution ( $\mathrm{pH} 10.25$ ) that contained either 0 (control: $\mathrm{n}=3$; glycerol: $\mathrm{n}=4$ ) or 5 (glucagon: $\mathrm{n}=3$; glucagon plus glycerol: $\mathrm{n}=4$ ) $\mathrm{mg}$ of glucagon. In addition, glycerol-treated cows received orally $400 \mathrm{~mL}$ of pure glycerol (West Central Inc., Ralston, IA) diluted with $100 \mathrm{~mL}$ of water once a day at $0600 \mathrm{~h}$ for 14 d. The presented results are from 14 cows that had prepartal liver samples. The remaining 6 cows in the study had calved before they were expected to, and thus, no prepartal liver sample had been collected. All the experimental and surgical procedures used in this study were approved by the Iowa State University Institutional Animal Care and Use Committee.

\section{Sampling and Analysis}

Blood and Milk. To monitor the long-term effect of treatments, a single blood sample was collected every other day from the coccygeal vein from $\mathrm{d}-7$ to $\mathrm{d} 15$ relative to parturition $1 \mathrm{~h}$ after treatment administration at $0700 \mathrm{~h}$. Twenty milliliters of blood was collected into 2 Vacutainer tubes (Tyco Health Care Group LP, Mansfield, MA) containing $\mathrm{Na}_{2}$-EDTA and placed on ice until plasma was separated by centrifugation at 500 $\times g$ for $20 \mathrm{~min}$ at $4^{\circ} \mathrm{C}$. Harvested plasma was stored at $-20^{\circ} \mathrm{C}$ until analysis for concentrations of glucose (kit number G7519-500, Pointe Scientific Inc., Canton, MI), NEFA (kit number 994-75409, Wako, Richmond, VA), BHBA (kit number H7587-58, Pointe Scientific Inc.), glycerol (kit number F 6428, Sigma, St. Louis, MO), and TAG (kit number T7532-120, Pointe Scientific Inc.) adapted for the microplate reader (SpectraMax Plus, Molecular Devices, Sunnyvale, CA). For plasma hormone determination, $1 \mathrm{~mL}$ of plasma was mixed with 500 KIU of aprotinin (Boehringer-Mannheim, Indianapolis, IN) and analyzed for plasma glucagon and insulin concentrations (kit number GL-32K and PI-12K, Linco Research Inc., St. Louis, MO). The daily milk production was recorded for the morning and evening and composited for the day.

Liver Tissue. Liver tissue samples were collected by ultrasound-guided puncture biopsy (Aloka Micrus 500, Corometrics Inc., Wallingford, CT) (Bobe et al., 2003a), following local anesthesia (2\% lidocaine hydrochloride), around $\mathrm{d}-4(\mathrm{~d}-10$ to $\mathrm{d}-2)$ and $\mathrm{d} 9$ relative to parturition. Liver tissue samples were rinsed with cold $0.9 \% \mathrm{NaCl}$, blotted free of moisture, and frozen in liquid nitrogen before storage at $-80^{\circ} \mathrm{C}$. Liver tissue samples were analyzed for total lipid, glycogen (Bobe et al., 2003a), and TAG (Hippen et al., 1999).

BCS and FLS-Related Health Disorders. Three individuals independently evaluated BCS 47 and $7 \mathrm{~d}$ before the expected calving date and at $\mathrm{d} 1,7$, and 14 postpartum. Because of technical difficulties with the Calan gates, no feed intake data are available. To monitor incidence of fatty liver-related health disorders, a comprehensive veterinary physical examination was conducted daily starting at $0600 \mathrm{~h}$. Urine ketone bodies, rectal temperature, and heart and respiratory rates were monitored daily. Signs of ketosis (urinary ketone body at $80 \mathrm{mg} / \mathrm{dL}$ ), unspecified fever, retained placenta, dysentery, milk fever, and laminitis were observed closely. Auscultation and percussion technique was applied on all cows for detection of left displaced abomasum.

\section{Statistical Analysis}

All outcome variables (i.e., concentrations of glucagon, insulin, glucose, BHBA, NEFA, and TAG in blood; concentrations of lipids, TAG, and glycogen in liver; milk production; and BCS) were analyzed as a repeatedmeasures study by using the mixed models procedure (PROC MIXED) of SAS Version 9.1.3 (SAS Institute Inc., Cary, NC). Concentrations of glucagon, insulin, BHBA, and NEFA in plasma were normalized by lntransformation. Orthogonal contrasts were constructed to determine effects of glucagon, oral glycerol, or both (i.e., glucagon vs. control, oral glycerol vs. control, glucagon plus glycerol vs. control) on all outcome variables using the ESTIMATE option in PROC MIXED. More specifically, we compared for blood variables changes during the treatment period [overall (d 1 to d 13), for each week (d 1 to d $5, \mathrm{~d} 7$ to d 13), for each time point] from prepartum (mean $\mathrm{d}-7$ to $\mathrm{d}-1$ ). For BCS, we compared changes during the treatment period $(\mathrm{d} 7, \mathrm{~d}$ 14 , or both) from pretreatment or start of treatment (mean d -9, d 1). For liver composition, we compared 

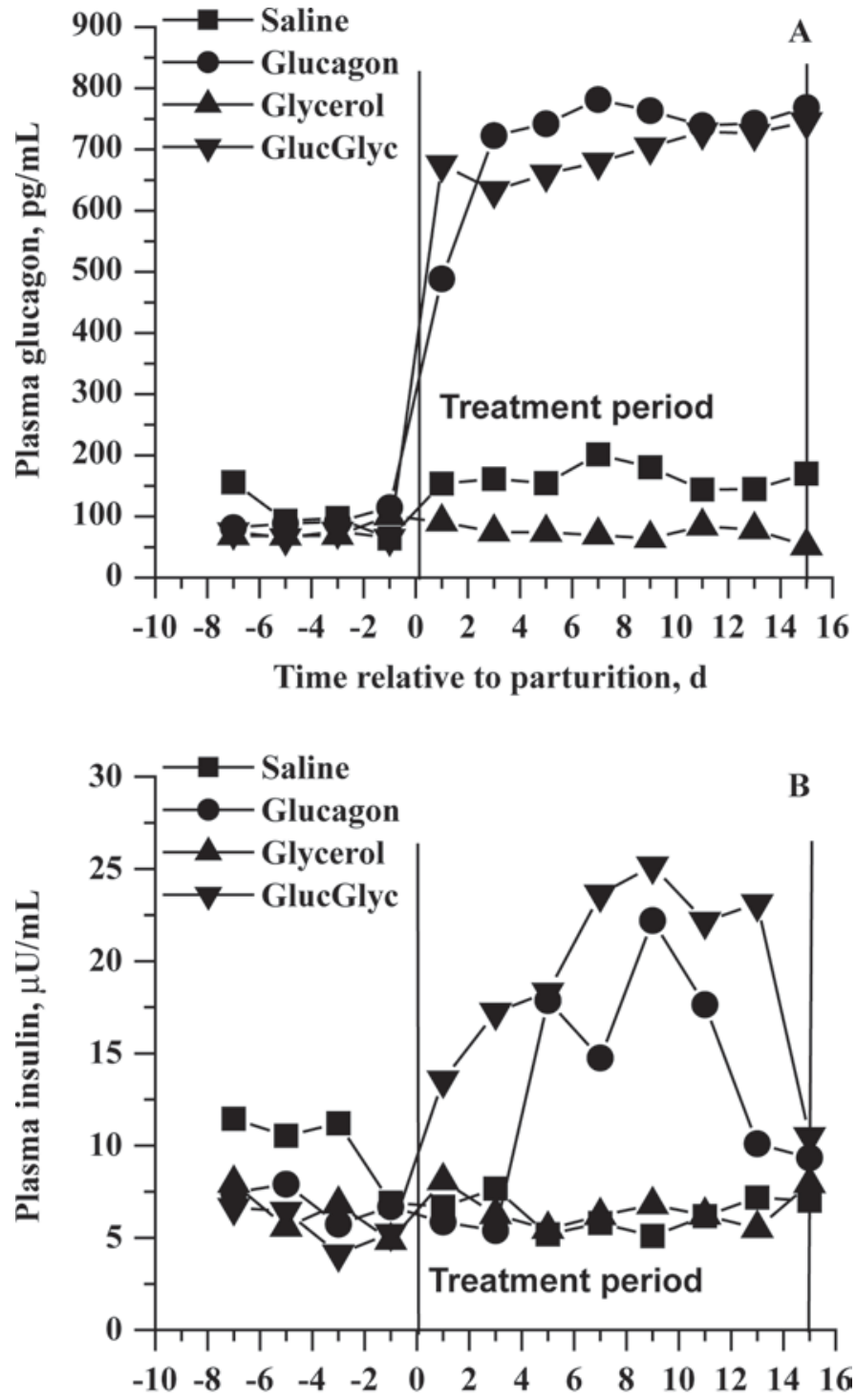

Time relative to parturition, $d$

Figure 1. Plasma hormone concentrations of cows treated with saline $(\mathrm{n}=3)$, glucagon $(\mathrm{n}=3)$, glycerol $(\mathrm{n}=4)$, or glucagon plus glycerol (GlucGlyc; $\mathrm{n}=4$ ). (A) Plasma glucagon concentration (SEM $=29.3$ to 59.6). Glucagon (overall: $P=0.001$; wk $1: P=0.0015$; wk 2: $P=0.002$ ) and glucagon plus glycerol (overall: $P=0.001$; wk $1: P$ $=0.002$; wk $2: P=0.0015)$ increased glucagon throughout the treatment period. Glycerol alone tended to decrease glucagon (overall: $P$ $=0.10$; wk 1: $P=0.57$; wk 2: $P=0.06)$, with $\mathrm{d} 7$ being significant. (B) Plasma insulin concentration (SEM $=2.5$ to 8.5). Glucagon alone increased insulin (overall: $P=0.05$; wk 1: $P=0.30$; wk 2: $P=0.02$ ), with significant increases starting at d 5 . Glycerol alone did not affect insulin at any time point (overall: $P=0.28$; wk $1: P=0.35$; wk $2: P$ $=0.33$ ). Glucagon plus glycerol increased insulin throughout the treatment period (overall: $P=0.002$; wk 1: $P=0.01$; wk $2: P=0.002$ ).

changes during treatment (d 9) from prepartum (d -4). For milk variables, we did not adjust for pretreatment values because treatments started directly after parturition. These comparisons were set up a priori. The comparisons slightly differ between outcome variables because of their different sampling schedules. In addition, we a posteriori compared glucagon plus glycerol versus glucagon to determine whether glycerol may potentiate the effect of glucagon. Because of the small number of liver samples, we a posteriori compared for liver composition glucagon versus no-glucagon treated cows and glycerol versus no-glycerol treated cows. The fixed effects in the mixed model were treatment (control, glucagon, glycerol, glucagon plus glycerol), time postpartum, and the interaction of treatment by time postpartum. For plasma and milk variables, we used in PROC MIXED a first-order autoregressive covariance structure that assumes that adjacent observations of the same cow tend to be more correlated than observations further apart in time, and for BCS and liver composition, we used an unrestricted covariance structure. The denominator degrees of freedom were adjusted for repeated measures using the KENWARDROGER option. The $P$-values were not adjusted for multiple comparisons. Significance was declared at $P \leq 0.05$, and trends toward significance were declared at $P \leq 0.10$. Means presented in figures are unadjusted means.

\section{RESULTS}

\section{Plasma Constituents}

Plasma Hormones. Exogenous glucagon alone or in combination with glycerol increased plasma glucagon concentrations throughout the injection period compared with the control treatment (Figure 1A). Interestingly, oral glycerol alone tended to decrease plasma glucagon concentrations in the second treatment week $(P=0.06)$, the decrease being significant at $\mathrm{d} 7$.

Exogenous glucagon alone primarily increased plasma insulin concentrations in the second treatment week (overall: $P=0.05$; wk 1: $P=0.30$; wk $2: P=0.03$ ), the effect being significant at d 5 (Figure 1B). Coadministration of glycerol potentiated and accelerated the effect of glucagon on plasma insulin concentrations, resulting in a significant insulin increase throughout the treatment period (overall: $P=0.0022$; wk $1: P=$ 0.01 ; wk 2: $P=0.002$ ). In comparison with exogenous glucagon alone, coadministration of glycerol increased plasma insulin concentrations in the second treatment week (overall: $P=0.05$; wk $1: P=0.30$; wk $2: P=$ 0.03), the effect being significant at d 3. Glycerol alone did not significantly affect plasma insulin concentrations at any time point.

Plasma Metabolites and Milk Production. Similarly to plasma insulin, exogenous glucagon alone increased plasma glucose concentrations in the second treatment week (overall: $P=0.02$; wk 1: $P=0.93$; wk 2: $P=0.00007)$, the effect being significant at $\mathrm{d} 7$ 

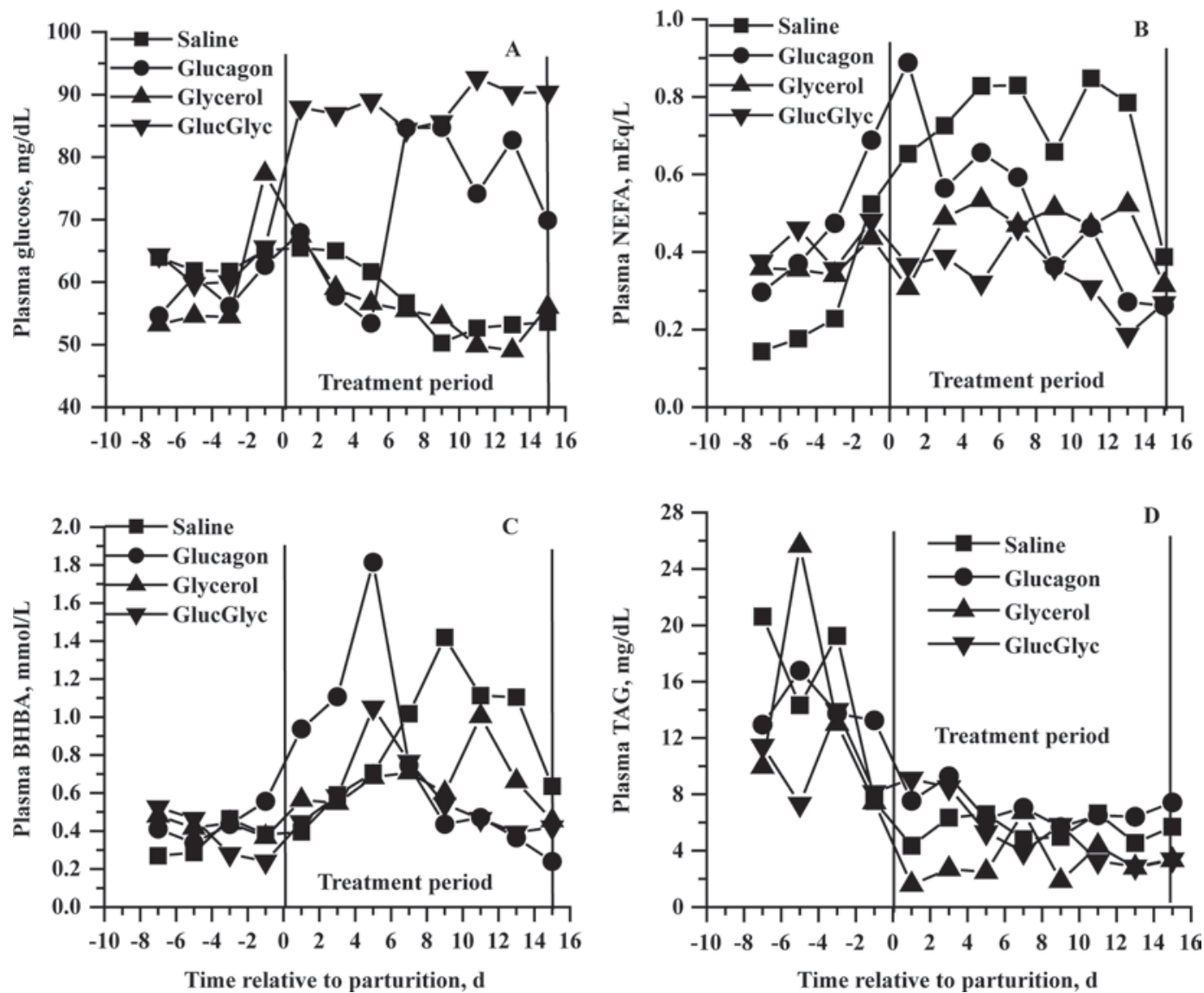

Figure 2. Plasma metabolites concentrations of cows treated with saline $(\mathrm{n}=3)$, glucagon $(\mathrm{n}=3)$, glycerol $(\mathrm{n}=4)$, or glucagon plus glycerol (GlucGlyc; $\mathrm{n}=4$ ). (A) Plasma glucose concentrations (SEM $=4.8$ to 9.7$)$. Glucagon alone increased glucose (overall: $P=0.02 ;$ wk $1: P=0.93$; wk 2: $P=0.0007$ ), with significant increases starting at $\mathrm{d} 7$. Glycerol alone did not affect glucose at any time point (overall: $P=0.96$; wk 1 : $P=0.95$; wk $2: P=0.81$ ). Glucagon plus glycerol increased glucose (overall: $P=0.0004$; wk $1: P=0.004$; wk $2: P=0.0004$ ), with significant increases starting at $\mathrm{d} 3$. (B) Plasma NEFA concentrations ( $\mathrm{SEM}=0.08$ to 0.20 ). Glucagon alone tended to decrease NEFA (overall: $P=0.08$; wk 1: $P=0.44$; wk 2: $P=0.04$ ), with significant decreases starting at d 9. Glycerol alone tended to decrease NEFA with no significant effects at any time point (overall: $P=0.07$; wk $1: P=0.10$; wk $2: P=0.10$ ). Glucagon plus glycerol decreased NEFA (overall: $P=0.005$; wk $1: P$ $=0.01$; wk 2: $P=0.005$ ), with significant decreases starting at d 3. (C) Plasma BHBA concentrations (SEM $=0.09$ to 0.68$)$. Glucagon alone decreased BHBA in the second treatment week (overall: $P=0.39$; wk 1: $P=0.32$; wk $2: P=0.03$ ), with decreases being significant at $\mathrm{d} 9$ and 13. Glycerol alone did not affect BHBA except for a significant decrease at d 9 (overall: $P=0.28$; wk $1: P=0.98$; wk 2: $P=0.12$ ). Glucagon plus glycerol did not affect BHBA concentrations at any time point (overall: $P=0.68$; wk 1: $P=0.91$; wk $2: P=0.48$ ). (D) Plasma triacylglycerol (TAG) concentrations ( $\mathrm{SEM}=6.4$ to 62.9 ). Glucagon (overall: $P=0.67$; wk $1: P=0.68$; wk $2: P=0.78$ ), glycerol $($ overall: $P=0.69$; wk 1: $P=0.52$; wk 2: $P=0.96$ ), and glucagon plus glycerol (overall: $P=0.23$; wk 1: $P=0.16$; wk $2: P=0.53$ ) did not change plasma TAG concentrations at any time point.

(Figure 2A). Coadministration of glycerol accelerated the effect of glucagon, resulting in a significant glucose increase at the third treatment day (overall: $P=$ 0.0004; wk 1: $P=0.004$; wk 2: $P=0.0004)$. In comparison with exogenous glucagon alone, coadministration of glycerol increased plasma glucose concentration in the first treatment week (overall: $P=0.06$; wk 1: $P=$ 0.003 ; wk $2: P=0.77$ ), the effect being significant at d 3 and 5. Glycerol alone did not significantly affect plasma glucose concentrations at any time point.

Exogenous glucagon alone decreased plasma NEFA concentrations in the second treatment week (overall:
$P=0.08$; wk $1: P=0.44$; wk $2: P=0.04)$, the effect being significant at d 9 (Figure 2B). Coadministration of glycerol accelerated the effect of glucagon on plasma insulin concentrations especially in the first treatment week, resulting in a significant NEFA decrease starting at the third treatment day (overall: $P=0.005$; wk 1: $P=0.01$; wk 2 : $P=0.0049)$. In comparison with exogenous glucagon alone, coadministration of glycerol decreased plasma NEFA concentrations in the first treatment week (overall: $P=0.10$; wk 1: $P=0.05$; wk 2: $P=0.30$ ), the effect being significant at $\mathrm{d} 1$. Glycerol alone tended to decrease NEFA concentrations, with 


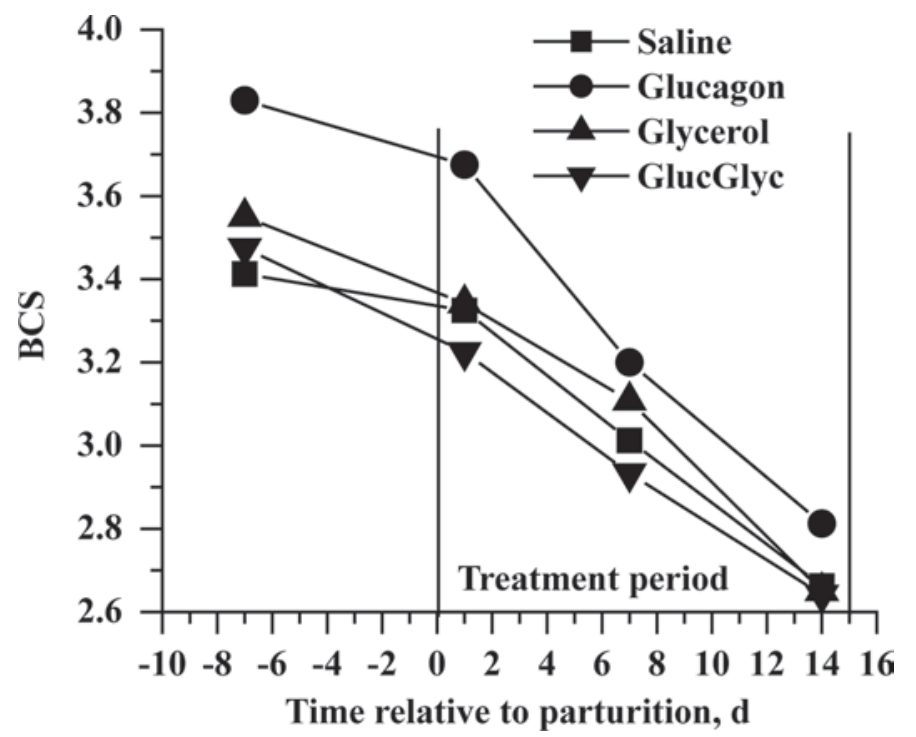

Figure 3. Body condition scores (SEM $=0.08$ to 0.12 ) of cows treated with saline $(\mathrm{n}=3)$, glucagon $(\mathrm{n}=3)$, glycerol $(\mathrm{n}=4)$, or glucagon plus glycerol (GlucGlyc; $\mathrm{n}=4$ ). Glucagon alone tended to decrease BCS (overall: $P=0.07 ; \mathrm{d} 7: P=0.14 ; \mathrm{d} 14: P=0.07$ ), whereas no significant changes were observed for cows receiving glycerol (overall: $P=0.80 ; \mathrm{d} 7: P=0.50 ; \mathrm{d} 14: P=0.27$ ) or glycerol plus glucagon (overall: $P=0.75 ; \mathrm{d} 7: P=0.67 ; \mathrm{d} 14: P=0.90$ ).

concentrations not being significantly decreased at any time point (overall: $P=0.07$; wk $1: P=0.10$; wk $2: P$ $=0.10)$.

Exogenous glucagon alone decreased plasma BHBA concentrations in the second treatment week (overall: $P=0.39$; wk $1: P=0.32$; wk $2: P=0.03$, the effect being significant at $\mathrm{d} 9$ and 13 (Figure 2C). Oral glycerol alone or in combination with glucagon did not affect plasma BHBA concentration at any time point during the treatment except for a significant decrease at d 9 for glycerol alone. Plasma TAG concentrations were not significantly changed by glucagon, glycerol, or both (Figure 2D).

Glucagon and glycerol, alone or in combination, did not significantly affect daily milk production. The results are not shown.
BCS and Fatty Liver-Related Health Disorders. Glucagon, glycerol, or both did not significantly change BCS; however, glucagon alone tended to decrease BCS (overall: $P=0.07$; $7: P=0.14$; d 14: $P=$ 0.07 ; Figure 3 ). The incidence of the fatty liver-related health disorders as percentages of all health disorders observed during the peripartal period were $33.3 \%$ for ketosis; $26.7 \%$ for milk fever; $13.3 \%$ for laminitis; and $6.7 \%$ for retained placenta, unspecified fever, dysentery, and left displaced abomasum (Table 1). Cows had one disorder except for one cow receiving glucagon alone that had both ketosis and laminitis and one cow receiving glucagon plus glycerol that had both milk fever and ketosis.

\section{Liver Composition}

Compared with the control treatment, glucagon and glycerol, alone or in combination, did not significantly alter liver composition, namely total lipids (Figure 4A), TAG (Figure 4B), and glycogen (Figure 4C). Glucagon in combination with glycerol tended to increase liver glycogen $(P=0.08$; Figure $4 \mathrm{C})$. In addition, glyceroltreated cows had smaller increases in total lipids than did cows receiving no glycerol $(P=0.05)$, and glucagontreated cows had smaller decreases in glycogen than did cows receiving no glucagon $(P=0.04)$.

\section{DISCUSSION}

The efficacy of exogenous glucagon to prevent and treat FLS is linked to its ability to increase hepatic glucose synthesis. The efficacy of glucagon, however, may be limited in the absence of sufficient available gluconeogenic precursors. The periparturient period with its low DMI is a critical time period for developing FLS and is a period in which cows may be low in available gluconeogenic precursors. Supplementation with gluconeogenic precursors may be required for glucagon to be effective in periparturient cows. In support, we previously reported that oral glycerol potentiated the action of glucagon on the first treatment day to in-

Table 1. Incidence of fatty liver-related peripartal health disorders of cows treated with saline $(\mathrm{n}=3)$, glucagon $(\mathrm{n}=3)$, glycerol $(\mathrm{n}=4)$, or glucagon plus glycerol $(\mathrm{n}=4)$ during the first $15 \mathrm{~d}$ of the postpartal period $^{1}$

\begin{tabular}{lccccccc}
\hline Treatment & Ketosis & LDA & RP & Laminitis & Fever & MF & Dysentery \\
\hline Saline & 1 & - & 1 & 1 & - & - & - \\
Glucagon & 2 & - & - & 1 & - & 1 & - \\
Glycerol & 1 & - & - & - & 1 & 1 & - \\
Glucagon plus glycerol & 1 & 1 & - & - & - & 2 & 1 \\
\hline
\end{tabular}

${ }^{1}$ LDA: left displacement of the abomasum; RP: retained placenta; MF: milk fever. Cows had one disorder except for one cow receiving glucagon alone that had both ketosis and laminitis and one cow receiving glucagon plus glycerol that had both milk fever and ketosis. 

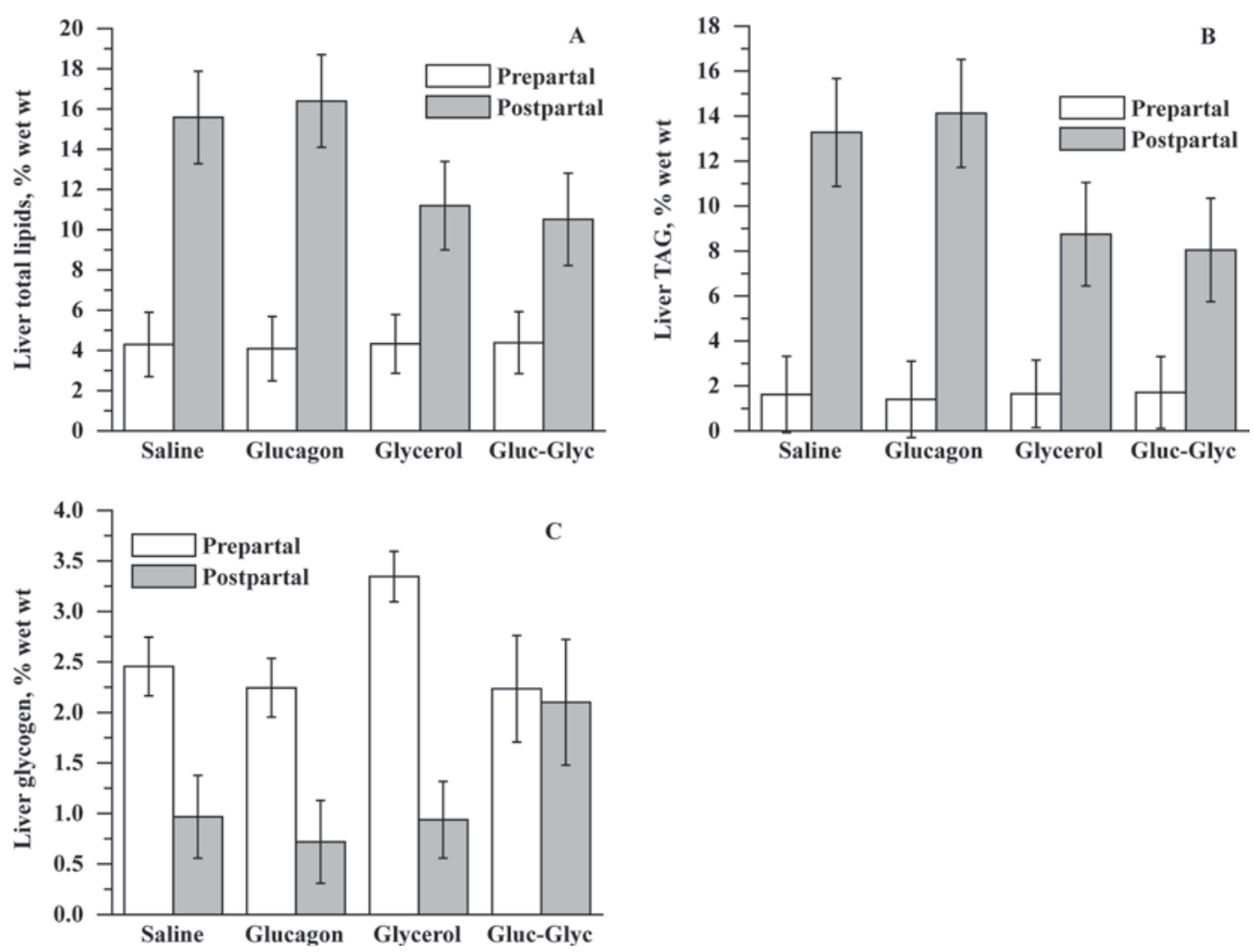

Figure 4. Liver composition on d 4 prepartum and d 9 postpartum of cows treated with saline $(\mathrm{n}=3)$, glucagon $(\mathrm{n}=3)$, glycerol $(\mathrm{n}=4)$, or glucagon plus glycerol (Gluc-Glyc; $\mathrm{n}=4$ ). (A) Liver total lipids percentage ( $\%$ wet wt; SEM $=2.20$ to 2.32 ). Glucagon $(P=0.84$ ), glycerol $(P=0.18)$, and glucagon plus glycerol $(P=0.17)$ did not affect total lipids changes. $(\mathrm{B})$ Liver triacylglycerol (TAG) percentage $(\%$ wet wt; SEM $=2.27$ to 2.39$)$. Glucagon $(P=0.31)$, glycerol $(P=0.78)$, and glucagon plus glycerol $(P=0.58)$ did not affect TAG changes. $(\mathrm{C})$ Liver glycogen percentage (\% wet wt; SEM $=0.38$ to 0.41$)$. Glucagon $(P=0.96)$ and glycerol $(P=0.21)$ did not affect glycogen changes, whereas glucagon plus glycerol tended to increase glycogen $(P=0.08)$.

crease plasma glucose and insulin and decrease NEFA, whereas no added benefit of glycerol was observed at $\mathrm{d}$ 7 and 13 of the treatment period (Osman et al., 2008). The current research focuses on glucagon- and glycerolinduced changes in plasma metabolites and hormones, liver composition, BCS, and milk production during the treatment period and showed that in the first treatment week, oral glycerol may potentiate the efficacy of exogenous glucagon to increase plasma glucose and insulin and decrease NEFA. Thus, in dairy cows, the combination of glucagon plus glycerol may be more effective than glucagon alone at the start of the treatment to prevent and alleviate some symptoms of FLS, such as the increase in plasma NEFA and the decrease in plasma glucose and insulin.

Administration of glucagon alone or in combination with glycerol increased plasma glucagon concentrations about 7-fold throughout the treatment period (Figure 1A), which indicated that the methodology of glucagon preparation and administration were effective (Hippen et al., 1999; Osman et al., 2008). Noteworthy is that glycerol treatment tended to decrease postpartal plasma glucagon concentration relative to that of the control group in the second treatment week (Figure 1A), which might indicate an improved energy status of the cows and that glycerol as a gluconeogenic substrate may influence glucagon secretion through a negative feedback loop.

In contrast to our earlier studies (Bobe et al., 2003a; Nafikov et al., 2006), glucagon alone did not increase plasma insulin concentrations until d 5 of glucagon administration (Figure 1B). The earlier treatment period (d 1 vs. d 3 and 8 postpartum in earlier studies) and the greater BCS for the glucagon-alone-treated cows in this study (3.83 vs. 3.5 and 3.6 in previous studies) may have impeded the effect of glucagon on insulin secretion. Oral glycerol may accelerate the effect of glucagon on insulin secretion by providing gluconeogenic precursors for hepatic synthesis of glucose, which, in turn, upregulates insulin secretion (Figure 1B). Consistent with the results of DeFrain et al. (2004), glycerol alone did not affect plasma insulin concentrations (Figure 1B). 
The effects of glucagon on plasma glucose concentrations were similar to those on plasma insulin (Figures $2 \mathrm{~A}$ and $1 \mathrm{C}$ ). Exogenous glucagon increases hepatic glucose synthesis by upregulating gluconeogenesis and glycogenolysis and downregulating glycolysis and glycogenesis; however, amount and type of substrate may alter the mechanism and efficacy (Hue, 1982; Hue and Bartrons, 1983). It is estimated that glycerol contributes about $4 \%$ of net hepatic glucose synthesis in the peripartal cow and primarily supplies energy through glycolysis in the form of ATP and pyruvate (Reynolds et al., 2003). If sufficient ATP is available, glycerol may be phosphorylated in the liver to form glyceraldehyde3-phosphate, which, in turn, could be converted to pyruvate and alanine for gluconeogenesis (Osman et al., 2008). Insufficient available ATP may inhibit the phosphorylation of glycerol and the use of glycerol as gluconeogenic precursor in the liver. In support of this contention, oral glycerol alone did not increase plasma glucose concentrations in this and other studies on early lactation dairy cows (Figure 2A; Bodarski et al., 2005; Osborne et al., 2009) unless larger doses of glycerol (1 to $3 \mathrm{~L}$ ) were used (Goff and Horst, 2001). Using glycerol in combination with glucagon may divert a larger proportion of glycerol from glycolysis to gluconeogenesis in the liver and thereby increase plasma glucose concentrations (Figure 2A).

In response to the glucagon-induced increase in plasma insulin and glucose, plasma NEFA concentrations decreased (Figure 2B), which is consistent with results from our previous studies (Hippen et al., 1999; Bobe et al., 2003b; Nafikov et al., 2006). It is likely that the increase of plasma glucose concentration stimulated by glucagon decreased the need for more lipolysis or that the greater plasma insulin concentrations might have inhibited protein kinase A and hormone-sensitive lipase (Degerman et al., 1997) or increased the reuptake and esterification of NEFA by adipose tissue (Brockman et al., 1975; Brockman and Laarveld, 1986). Oral glycerol accelerated and potentiated the effect of glucagon on decreasing NEFA concentrations (Figure 2B). One contributing factor might be the use of glycerol for conversion to $\alpha$-GP to esterify excess NEFA into TAG in adipose tissue. In support of this contention, plasma NEFA and TAG tended to be inversely associated in cows that were treated with glucagon plus glycerol, whereas they were associated positively in the other treatment groups (Osman et al., 2008). In addition, glycerol alone tended to decrease NEFA concentrations (Figure 2B).

Consistent with results from our previous studies (Bobe et al., 2003b,c; Nafikov et al., 2006), exogenous glucagon alone decreased plasma BHBA concentration in the second treatment week (Figure 2C), which closely agrees with its effects on plasma glucose, insulin, and NEFA during the same time (Figures $2 \mathrm{~A}, 1 \mathrm{~B}$, and $2 \mathrm{~B}$ ). Glycerol alone or in combination with glucagon did not decrease plasma BHBA concentrations, which is consistent with the results by DeFrain et al. (2004). Ruminal fermentation of glycerol produces propionate, acetate, and some butyrate, which tends to increase plasma BHBA concentrations (Bodarski et al., 2005; Remond et al., 1993; DeFrain et al., 2004). Thus, greater BHBA concentrations in glycerol-fed cows may indicate an increased ruminal fermentation of glycerol rather than an impaired hepatic tricarboxylic acid cycle activity and pathogenesis of ketosis.

Plasma TAG concentrations were not altered by long-term glucagon alone, glycerol alone, or in combination (Figure 2D). Plasma TAG steeply decreased on d 1 postpartum and became lesser than the prepartal concentrations for all treatment groups (Figure 2D). A similar decrease of plasma TAG during the early postpartal period was reported by Bobe et al. (2003a). The decrease of plasma TAG concentration could be caused by the increased availability of $\alpha$-GP (Osman et al., 2008) in adipose tissue coupled with the decrease of very low-density lipoprotein (Grummer, 1993) during the postpartal period in liver. As the dairy cow proceeds through the transition period, metabolism of TAG seldom changes (Reynolds et al., 2003).

Even though the number of cows was relatively small, incidence of fatty liver-related peripartal health disorders as percentages of total postpartal health disorders indicated prevalence of ketosis, milk fever, and laminitis (Table 1). The high incidence of ketosis in this study indicates the intimate relationship with FLS as a cause of ketosis (Goff, 2006).

Compared with the control treatment, glucagon, glycerol, or both did not alter total liver lipids and TAG concentrations at d 9 postpartum (Figures $4 \mathrm{~A}$ and $4 \mathrm{~B}$ ). However, glycerol significantly attenuated the increase in liver lipid concentrations when both glycerol-treated groups were combined compared with cows that did not receive glycerol. The ability of glycerol to provide $\alpha$-GP, which facilitates the esterification of excess NEFA in adipose tissue, may have attenuated the increase in liver lipid concentrations in the cows receiving glycerol. A potential reason why we did not observe a protective effect of glucagon on liver lipids and TAG is that cows receiving glucagon alone started with a greater BCS and had no changes in plasma glucose, insulin, NEFA, and BHBA until the second treatment week.

Liver glycogen concentrations (wet wt \%) were not significantly altered in cows receiving glucagon alone for $9 \mathrm{~d}$ (Figure 4C) because glucagon initially causes depletion of liver glycogen followed by replenishment as a result of the concurrent increase of glucose and 
insulin in the second week of glucagon treatment (Hippen et al., 1999; Bobe et al., 2003a,b). Glucagon plus glycerol immediately increased glucose production and insulin secretion, and, thus, liver glycogen was almost fully replenished on d 9 postpartum and tended to be greater compared with that of cows in the control group (Figure 4C). Glycerol alone did not increase liver glycogen content because glycerol alone probably did not increase hepatic glucose synthesis as indicated by the unchanged plasma glucose concentrations (Figures $2 \mathrm{~A}$ and $4 \mathrm{C})$.

\section{CONCLUSION}

The data presented here suggest that glycerol has the potential to enhance the long-term effect of glucagon on alleviating some symptoms of FLS, such as the increase in plasma NEFA and the decrease in plasma glucose and insulin, in Holstein dairy cows after parturition. A study that uses a larger number of experimental cows with homogeneous BCS is warranted to establish stronger evidence. A slow-release subcutaneous glucagon implant that releases $5 \mathrm{mg}$ of glucagon each $8 \mathrm{~h}$ coadministered with slowly dissolving oral glycerol paste in the early treatment days could be tested for efficacy.

\section{ACKNOWLEDGMENTS}

The authors thank Eli Lilly (Indianapolis, IN) for donation of glucagon, the USDA for financing the study (grant number 2002-02060), and the management of Iowa State University Teaching Dairy Farm at Ankeny, Iowa, for providing the research cows. Our thanks are extended to Derek Widman (Department of Animal Science, Iowa State University) for assisting with sampling and to Gayle Johnson (Department of Chemistry, Iowa State University) for assisting with laboratory analyses.

\section{REFERENCES}

Bobe, G., B. N. Ametaj, J. W. Young, and D. C. Beitz. 2003a. Effects of exogenous glucagon on lipids in lipoproteins and liver of lactating dairy cows. J. Dairy Sci. 86:2895-2903.

Bobe, G., B. N. Ametaj, J. W. Young, and D. C. Beitz. 2003b. Potential treatment of fatty liver with 14-day subcutaneous injection of glucagon. J. Dairy Sci. 86:3138-3147.

Bobe, G., R. N. Sonon, B. N. Ametaj, J. W. Young, and D. C. Beitz 2003c. Metabolic responses of lactating dairy cows to single and multiple subcutaneous injection of glucagon. J. Dairy Sci. 86:2072-2081.

Bobe, G., J. C. Velez, D. C. Beitz, and S. S. Donkin. 2009. Glucagon increases hepatic mRNA levels of gluconeogenic and ureagenic enzymes in early lactation dairy cows. J. Dairy Sci. 92:50925099.

Bodarski, R., T. Wertelecki, F. Bommer, and S. Gosiewski. 2005. The changes of metabolic status and lactation performance in dairy cows under feeding TMR with glycerin (glycerol) supplement at periparturient period. Electronic J. Polish Agric. Univ. 8. http:// www.ejpau.media.pl/volume8/issue4/abs-22.html Accessed Aug. 9, 2009.

Brockman, R. P., E. N. Bergman, P. K. Joo, and J. G. Manns. 1975. Effects of glucagon and insulin on net hepatic metabolism of glucose precursors in sheep. Am. J. Physiol. 229:1344-1349.

Brockman, R. P., and B. Laarveld. 1986. Hormonal regulation of metabolism in ruminants: A review. Livest. Prod. Sci. 14:313334.

DeFrain, J. M., A. R. Hippen, K. F. Kalscheur, and P. W. Jardon. 2004. Feeding glycerol to transition dairy cows: Effects on blood metabolites and lactation performance. J. Dairy Sci. 87:41954206.

Degerman, E., P. Belfrage, and V. C. Manganiello. 1997. Structure, localization, and regulation of cGMP-inhibited phosphodiesterase (PDE3). J. Biol. Chem. 272:6823-6826.

Doepel, L., H. Lapierre, and J. J. Kennelly. 2002. Peripartum performance and metabolism of dairy cows in response to prepartum energy and protein intake. J. Dairy Sci. 85:2315-2334.

Goff, J. P. 2006. Major advances in our understanding of the nutritional influences on bovine health. J. Dairy Sci. 89:1292-1301.

Goff, J. P., and R. L. Horst. 2001. Oral glycerol as an aid in the treatment of ketosis/fatty liver complex. J. Dairy Sci. 84(Suppl. 1):153-154.

Greenfield, R. B., M. J. Cecava, T. R. Johnson, and S. S. Donkin. 2000. Impact of dietary protein amount and rumen undegradability on intake, peripartum liver triglyceride, plasma metabolites, and milk production in transition dairy cattle. J. Dairy Sci. 83:703-710.

Grummer, R. R. 1993. Etiology of lipid-related metabolic disorders in periparturient dairy cows. J. Dairy Sci. 76:3882-3896.

Hayirli, A., R. R. Grummer, E. V. Nordheim, and P. M. Crump. 2002. Animal and dietary factors affecting feed intake during the prefresh transition period in Holsteins. J. Dairy Sci. 85:3430-3443.

Hippen, A. R., P. She, J. W. Young, D. C. Beitz, G. L. Lindberg, L. F. Richardson, and R. W. Tucker. 1999. Alleviation of fatty liver in dairy cows with 14-day intravenous infusion of glucagon. J. Dairy Sci. 82:1139-1152.

Hoedemaker, M., D. Prange, H. Zerbe, J. Frank, A. Daxenberger, and H. H. D. Meyer. 2004. Peripartal propylene glycol supplementation and metabolism, animal health, fertility and production in dairy cows. J. Dairy Sci. 87:2136-2145.

Hue, L. 1982. Role of fructose 2,6 bisphosphate in the stimulation of glycolysis by anoxia in isolated hepatocytes. Biochem. J. 206:359365.

Hue, L., and R. Bartrons. 1983. Role of fructose 2,6 bisphosphate in the control by glucagon of gluconeogenesis from various precursors in isolated rat hepatocytes. Biochem. J. 218:165-170.

Nafikov, R. A., B. N. Ametaj, G. Bobe, K. J. Koehler, J. W. Young, and D. C. Beitz. 2006. Prevention of fatty liver in transition dairy cows by subcutaneous injection of glucagon. J. Dairy Sci. 89:1533-1545.

NRC. 2001. Nutrient Requirements for Dairy Cattle. 7th rev. ed. Natl. Acad. Press, Washington, DC.

Osborne, V. R., N. E. Odongo, J. P. Cant, K. C. Swanson, and B. W. McBride. 2009. Effects of supplementing glycerol and soybean oil in drinking water on feed and water intake, energy balance and production performance in periparturient dairy cows. J. Dairy Sci. 92:698-707.

Osman, M. A., P. S. Allen, N. A. Mehyar, G. Bobe, J. F. Coetzee, K. J. Koehler, and D. C. Beitz. 2008. Acute metabolic responses of postpartal dairy cows to subcutaneous glucagon injection, oral glycerol or both. J. Dairy Sci. 91:3311-3322.

Remond, B., E. Souday, and J. P. Jouany. 1993. In vitro and in vivo fermentation of glycerol by rumen microbes. Anim. Feed Sci. Technol. 41:121-132.

Reynolds, C. K., P. C. Alikman, B. Lupoli, D. J. Humphries, and D. E. Beever. 2003. Splanchnic metabolism of dairy cows during the transition from late gestation through early lactation. J. Dairy Sci. 86:1201-1217. 